\title{
EDITORIAL TO THIS SPECIAL ISSUE IN MEMORY OF LACI KOVÁCS
}

This special issue of the Journal of the Australian Mathematical Society is dedicated to the memory of László György Kovács. Laci as he was known to his friends and colleagues, passed away on Sunday 28th July, 2013 at the age of 76. Born and raised in Hungary, Laci received his mathematical education there and later in England. Most of his working life was spent in Australia, where he moved in 1963 to work at the Australian National University (ANU) in the research mathematics department being built up by B. H. (Bernhard) Neumann. He was one of the key figures, alongside Bernhard and Hanna Neumann, M. F. (Mike) Newman, and others, who turned Canberra into a leading international centre of group theory. Laci stayed at the ANU until his retirement in 2001, and afterwards as a Retired Visiting Fellow.

Laci was an eminent mathematician who made profound contributions to a number of areas of algebra. He was a brilliant communicator of mathematics, both in writing and as a speaker. The complete published works of Laci are available at The Laci Kovács Archive; see

$$
\text { http://archives.maths.anu.edu.au/people/Kovacs/. }
$$

We thank the Mathematical Sciences Institute of the Australian National University, and in particular Professor M. F. Newman and Dr Scott Morrison, for constructing this archive. Laci's teaching and research supervision was deeply thoughtful; it continues to shape the careers of his students.

This issue contains five survey articles devoted to various aspects of Laci's mathematical work (varieties of groups, permutation groups, linear groups, representation theory, and Lie representations) and a number of original research articles. A detailed obituary by Laci's friend and colleague Mike Newman is reprinted here with permission from the Gazette of the Australian Mathematical Society. A delightful, and mathematically insightful, example of Laci's brilliant writing is a letter he wrote to Charles Curtis explaining a 'characteristic-free' extension of a lemma of Richard Brauer. This two-page letter was published by the Bulletin of the London Mathematical Society (in the original letter format), and we reprint it here with thanks to the London Mathematical Society.

We are greatly indebted to the editors-in-chief of this journal, and to Judith Borwein, for making this special issue possible. Our special thanks go to Mike Newman for his invaluable advice and support in preparing the issue. Finally, we thank all contributors and referees, especially those who accepted our invitation to contribute surveys on aspects of Laci's work. 
Laci is dearly remembered by many people around the world-his students, colleagues, collaborators, and friends, some of whom have contributed to this issue. He will be remembered for his kindness, generosity, and warmth. He was widely interested in all things cultural, especially music and art. Conversation with him was always interesting and enlightening, and many people who knew him will recall things he introduced them to, and the insights he shared. Laci had many friends and he will be greatly missed.

Managing editor: S. P. GLASBY

Editors: DANE FLANNERY, CHERYL E. PRAEGER, RALPH STÖHR 